\title{
The endogenous cannabinoid system protects against colonic inflammation
}

\author{
Federico Massa, ${ }^{1,2}$ Giovanni Marsicano, ${ }^{1}$ Heike Hermann, ${ }^{1}$ Astrid Cannich, ${ }^{1}$ Krisztina Monory, ${ }^{1}$ \\ Benjamin F. Cravatt, ${ }^{3}$ Gian-Luca Ferri, ${ }^{2}$ Andrei Sibaev, ${ }^{4}$ Martin Storr, ${ }^{4}$ and Beat Lutz ${ }^{1}$
}

\begin{abstract}
${ }^{1}$ Group Molecular Genetics of Behaviour, Max Planck Institute of Psychiatry, Munich, Germany. ${ }^{2}$ Neuro-Endocrine Fluorescence Laboratory, Department of Cytomorphology, University of Cagliari, Cagliari, Italy. ${ }^{3}$ Skaggs Institute for Chemical Biology and Department of Cell Biology, The Scripps Research Institute, La Jolla, California, USA. 4 II Medical Department, Klinikum Grosshadern,
\end{abstract}

Ludwig Maximilians University of Munich, Munich, Germany.

\begin{abstract}
Excessive inflammatory responses can emerge as a potential danger for organisms' health. Physiological balance between pro- and anti-inflammatory processes constitutes an important feature of responses against harmful events. Here, we show that cannabinoid receptors type 1 (CB1) mediate intrinsic protective signals that counteract proinflammatory responses. Both intrarectal infusion of 2,4-dinitrobenzene sulfonic acid (DNBS) and oral administration of dextrane sulfate sodium induced stronger inflammation in $\mathrm{CB} 1$-deficient mice $\left(\mathrm{CB1}^{-/-}\right)$than in wild-type littermates $\left(\mathrm{CB1}^{+/+}\right)$. Treatment of wild-type mice with the specific CB1 antagonist $N$-(piperidino-1-yl)-5-(4-chlorophenyl)-1-(2,4-dichlorophenyl)-4-methyl-pyrazole-3carboxamide (SR141716A) mimicked the phenotype of $\mathrm{CB1}^{-/-}$mice, showing an acute requirement of $\mathrm{CB} 1$ receptors for protection from inflammation. Consistently, treatment with the cannabinoid receptor agonist $R(-)$-7-hydroxy- $\Delta^{6}$-tetra-hydrocannabinol-dimethylheptyl (HU210) or genetic ablation of the endocannabinoid-degrading enzyme fatty acid amide hydrolase (FAAH) resulted in protection against DNBSinduced colitis. Electrophysiological recordings from circular smooth muscle cells, performed 8 hours after DNBS treatment, revealed spontaneous oscillatory action potentials in $\mathrm{CB1}^{-/-}$but not in $\mathrm{CB1}^{+/+}$colons, indicating an early CB1-mediated control of inflammation-induced irritation of smooth muscle cells. DNBS treatment increased the percentage of myenteric neurons expressing CB1 receptors, suggesting an enhancement of cannabinoid signaling during colitis. Our results indicate that the endogenous cannabinoid system represents a promising therapeutic target for the treatment of intestinal disease conditions characterized by excessive inflammatory responses.
\end{abstract}

\section{Introduction}

Colon pathologies span a wide range of different conditions, including frankly inflammatory bowel diseases (ulcerative colitis and Crohn disease) and so-called functional bowel diseases (e.g., irritable bowel syndrome), and represent an important and widespread health problem in modern society $(1,2)$. The occurrence of an enteric infection, trauma, or inflammation has been suggested to be related to the initiation of these diseases $(2,3)$. During the last decade, several experimental animal models of inflammatory bowel diseases have been developed to define the different components of the pathophysiological processes that characterize these disorders. Among these models, the intrarectal administration of 2,4-dinitrobenzene sulfonic acid (DNBS) and the oral administration of dextrane sulfate sodium (DSS) have been extensively used to study the mechanisms of colonic inflammation and to test anti-inflammatory drugs $(4,5)$. Infections, traumata, or chemical insults are believed to induce sever-

Nonstandard abbreviations used: 2-arachidonoyl-glycerol (2-AG); cannabinoid receptor type 1 (CB1); cannabinoid receptor type 2 (CB2); dextrane sulfate sodium (DSS); 2,4-dinitrobenzene sulfonic acid (DNBS); fatty acid amide hydrolase (FAAH); hexa-decyl-trimethyl-ammonium bromide (HTAB); in situ hybridization (ISH); myeloperoxidase (MPO); $N$-(piperidino-1-yl)-5-(4-chlorophenyl)-1-(2,4-

dichlorophenyl)-4-methyl-pyrazole-3-carboxamide (SR141716A); preproenkephalin (Enk); resting membrane potential (RMP); $R(-)-7$-hydroxy- $\Delta^{6}$-tetra-hydrocannabinoldimethylheptyl (HU210).

Conflict of interest: The authors have declared that no conflict of interest exists.

Citation for this article: J. Clin. Invest. 113:1202-1209 (2004).

doi:10.1172/JCI200419465. al cellular reactions, which eventually lead to an inflammatory status of the colon. At the same time, however, protective mechanisms aimed at preventing the pathological outcome of proinflammatory insults are also induced. Hence, the overall balance between pro- and anti-inflammatory mechanisms is likely to determine the progression and severity of colitis. A better understanding of intrinsic mechanisms that protect against inflammation would provide an effective starting point for development of novel therapeutic treatments.

The major active constituent of the plant Cannabis sativa (marijuana), $\Delta^{9}$-tetrahydrocannabinol, and a variety of natural and synthetic cannabinoids have been shown to possess antinociceptive and anti-inflammatory activities (6-8). For millennia, Cannabis preparations have been used in folk medicine for the treatment of a wide variety of disorders, including those affecting the gastrointestinal tract (9). A century ago, extracts of Cannabis were used in the US to treat gastrointestinal pain of different origins, gastroenteritis, and diarrhea. There are also anecdotal reports suggesting that marijuana may be effective in alleviating symptoms of Crohn disease (10). Most of the biological actions of cannabinoids are mediated by two types of cannabinoid receptors, CB1 and CB2, both coupled to G proteins (11-13). Endogenous ligands for cannabinoid receptors (endocannabinoids) such as the agonists anandamide and 2-arachidonoyl-glycerol (2-AG) are lipidic messengers derived from arachidonic acid (11-13). After synthesis in the cell membrane, release into extracellular space, and action at cannabinoid receptors, endocannabinoids are 
rapidly inactivated by cellular uptake and degradation mediated by specific enzymes, among which the best-characterized is fatty acid amide hydrolase (FAAH) (12-14). The discovery of endocannabinoids and the characterization of the mechanisms for their synthesis and degradation evidenced the existence of the endogenous cannabinoid system, which exerts many physiological functions. Functional CB1 receptors are present on enteric neurons (15-20), and the gastrointestinal tract produces at least two endocannabinoids, namely anandamide and 2-AG $(8,20,21)$. In fact, the endogenous cannabinoid system plays a role in the control of various functions, including gastroprotection, intestinal motility, and secretion (8). In the present investigation, we examined the role of the endogenous cannabinoid system after inflammatory insults in the colon and show that this system provides intrinsic protection against colonic inflammation.

\section{Methods}

Animals. Eight- to ten-week-old CB1-deficient $\left(\mathrm{CB}^{-/-}\right)$and FAAH-deficient $\left(\mathrm{FAAH}^{-/-}\right)$female mice and corresponding wildtype littermates were used for experiments $(22,23)$. Mice were in mixed genetic background, with a predominant C57BL/ $6 \mathrm{~N}$ contribution (five backcrosses for both mutant lines). Eight- to tenweek-old female C57BL/6N mice were purchased from Charles River Wiga GmbH (Sulzfeld, Germany). Mice were housed under standard conditions and supplied with drinking water and food ad libitum. All animal procedures complied with the guidelines for care and use of laboratory animals of the government of the state of Bavaria, Germany.

Materials. DNBS was purchased from ICN Biomedicals $\mathrm{GmbH}$ (Eschwege, Germany), DSS from Sigma-Aldrich (Taufkirchen, Germany), and $R$ (-)-7-hydroxy- $\Delta^{6}$-tetra-hydrocannabinol-dimethylheptyl (HU210) from Tocris Cookson Ltd. (Bristol, United Kingdom). $N$-(piperidino-1-yl)-5-(4-chlorophenyl)-1-(2,4-dichlorophenyl)-4methyl-pyrazole-3-carboxamide (SR141716A) was a gift from the National Institute of Mental Health's Chemical Synthesis and Drug Supply Program (USA).

Induction of colitis. After 36 hours of starving, colitis was induced by intrarectal administration of DNBS ( $5 \mathrm{mg}$ per mouse) using a modification (24) of the method first described in rats (25). In pilot experiments, this dose of DNBS was found to induce reproducible colitis without mortality in heterozygous $C B 1^{+/-}$mice (data not shown). Briefly, mice were lightly anesthetized with isoflurane, and DNBS (5 mg in $100 \mu \mathrm{l}$ of 50\% ethanol) was infused into the rectum through a catheter (outer diameter $0.8 \mathrm{~mm}$ ), inserted $4-5 \mathrm{~cm}$ proximally to the anus. Solvent alone $(100 \mu \mathrm{l}$ of $50 \%$ ethanol) was administered in control experiments. Colitis was also induced by oral administration of DSS ( $5 \%$ in drinking water for 7 days) as described in ref. 26.

Pharmacological treatments. Drugs were injected subcutaneously (20 $\mathrm{ml} / \mathrm{kg}$ body weight) under light isoflurane anesthesia. SR141716A (3 mg/kg body weight) and HU210 (0.05 mg/ $\mathrm{kg}$ body weight) were dissolved in vehicle solution (one drop of Tween-80 in $3 \mathrm{ml} 2.5 \%$ dimethylsulfoxide in saline) and injected 30 minutes before and 24 hours and 48 hours after DNBS infusion. Vehicle solution was used in control experiments.

Evaluation of colonic damage. Mice were killed by cervical dislocation 3 days after DNBS treatment, unless otherwise specified, or 7 days after continuous DSS treatment. The colon was removed and rinsed gently with saline solution, then opened by longitudinal incision and examined immediately. Colonic damage was assessed by a semiquantitative scoring system originally established in rats (27) and adapted to mice for the present study. Morphology was scored according to the following scale: 0 , no damage; 1 , localized hyperemia without ulcers; 2 , linear ulcers without significant inflammation; 3 , one site of ulceration or inflammation; 4, two or more sites of ulceration or inflammation with a total extension less than $1 \mathrm{~cm} ; 5$, two or more sites of ulceration or inflammation with a total extension more than $1 \mathrm{~cm}$ longitudinally; $6-10$, if damage covered more than $1 \mathrm{~cm}$ longitudinally, the score is increased by 1 for each additional $0.5 \mathrm{~cm}$ of damage. In the presence of diarrhea, the score is increased by 1 .

Determination of tissue myeloperoxidase activity. Samples of colon were weighed, frozen, and processed for determination of myeloperoxidase (MPO) activity. MPO activity represents an index of neutrophil accumulation $(28,29)$. Tissue was suspended in hexadecyl-trimethyl-ammonium bromide (HTAB) buffer $(0.5 \%$ HTAB [Sigma-Aldrich] in $50 \mathrm{mM}$ potassium phosphate buffer, $\mathrm{pH} 6.0 ; 50$ $\mathrm{mg}$ of tissue $/ \mathrm{ml}$ ) and disrupted using a homogenizer. HTAB is a detergent that releases MPO from the primary granules of neutrophils. After one freezing/thawing cycle of the homogenate and centrifugation (15-30 minutes, $16,000 \mathrm{~g}, 4^{\circ} \mathrm{C}$ ), $0.1 \mathrm{ml}$ of supernatant was added to $2.9 \mathrm{ml}$ of $50 \mathrm{mM}$ potassium phosphate buffer ( $\mathrm{pH}$ 6.0) containing $0.167 \mathrm{mg} / \mathrm{ml}$ of $O$-dianisidine hydrochloride and $0.05 \% \mathrm{H}_{2} \mathrm{O}_{2}$. Absorbance was measured at $460 \mathrm{~nm}$ (Beckman $640 \mathrm{U}$ photometer; Beckman Coulter GmbH, Unterschleißheim, Germany). MPO was expressed in milliunits per gram of wet tissue, 1 unit being the quantity of enzyme able to convert $1 \mu$ mol of $\mathrm{H}_{2} \mathrm{O}_{2}$ to water in 1 minute at room temperature. Units of MPO activity per minute were calculated from a standard curve using purified peroxidase enzyme (Sigma-Aldrich). As considerable variations in the magnitude of the MPO values were observed between batches of animals studied during a 12-month period, data for each experiment were normalized to the value obtained in control groups.

In situ bybridization and neuron counting. After isolation, the colons were snap-frozen on dry ice and stored at $-80^{\circ} \mathrm{C}$ until sectioning. The colons were mounted on Tissue-Tek (Polysciences Europe $\mathrm{GmbH}$, Eppelheim, Germany), and $20-\mu \mathrm{m}$-thick transverse sections were cut on a cryostat Microtome HM 560 (Microm International $\mathrm{GmbH}$, Braunschweig, Germany). Sections were mounted onto frozen Superfrost Plus slides (Fisher Scientific GmbH, Hannover, Germany), dried on a $42^{\circ} \mathrm{C}$ warming plate, and stored at $-20^{\circ} \mathrm{C}$ until use. ${ }^{35} \mathrm{~S}$-labeled riboprobe for $\mathrm{CB} 1$ and preproenkephalin (Enk) were used for in situ hybridization (ISH). The probe for CB1 was generated as described previously $(30,31)$. The cDNA for the generation of the Enk riboprobe was synthesized by RT-PCR on whole mouse-brain RNA preparation, using the primers 5'-TGCACACTGGAATGTGAAGGA and 5'-CACAGACCCTAAAATCACAGC, corresponding to bp 57-77 and 887-867, respectively, of GenBank accession no. M13227. ISH and subsequent exposure to photographic emulsion (Kodak NTB-2 [Sigma-Aldrich] diluted 1:1 in distilled water) were carried out as described in detail in ref. 30 .

Parallel sections, adjacent to the ones used for ISH, were fixed for 1 hour in Carnoy solution and were stained with cuprolinic blue (32) for total counts of myenteric neurons. The staining solution $(0.3 \%$ cuprolinic acid and $1 \mathrm{M} \mathrm{MgCl}_{2}$ in $0.025 \mathrm{M}$ sodium acetate buffer, $\mathrm{pH}$ 5.6) was applied for 60 minutes at room temperature, and the sections were then rinsed in distilled water and placed in sodium acetate buffer ( $\mathrm{pH}$ 5.6) containing $1 \mathrm{M} \mathrm{MgCl}_{2}$. Finally, sections were rinsed in distilled water, placed in ethanol and xylene, and then mounted in DPX 
(BDH Chemicals Ltd., Poole, United Kingdom). CB1-positive, Enkpositive, and cuprolinic blue-positive neurons (total population) were counted on four to six randomly chosen sections for each animal (three animals per group) by two independent observers blinded to animals' treatment and genotype. On each section, the length of serosa was measured, and the average number of cells per millimeter of serosal length was calculated for each mouse. Data were expressed as percentage of control groups (untreated $C B 1^{+/+}$mice).

Electrophysiological experiments. The colon was exposed by an abdominal midline incision. The complete large bowel was removed and placed into oxygenated Krebs solution of the following composition (in $\mathrm{mM}$ ): $\mathrm{NaCl} 120.5, \mathrm{KCl} 5.9, \mathrm{MgCl}_{2} 2.5, \mathrm{NaH}_{2} \mathrm{PO}_{4} 1.2$, $\mathrm{NaHCO}_{3}$ 15.5, $\mathrm{CaCl}_{2}$ 2.5, glucose 11.5, pH 7.4. The colon was opened along the mesenteric border, washed of remaining fecal material, and pinned out in a Sylgard-lined dissecting dish (Dow Corning Corp., Midland, Michigan, USA) containing oxygenated Krebs solution. The distal colon was separated, and mucosa and submucosa were removed, resulting in sheets of tissue consisting of circular and longitudinal muscle layers, together with the attached myenteric plexus. The sheets of distal colon were pinned using $150-200$ wolfram wire micropins $(15-25 \mu \mathrm{m}$ in thickness) to the Sylgard-based electrophysiological chamber with the circular muscle layer uppermost. Experiments with $\mathrm{CB1}^{-/-}$and wild-type littermates at the same time point after induction of inflammation were performed simultaneously in one electrophysiological chamber. The chamber was perfused $(5 \mathrm{ml} / \mathrm{min}$; Kwik-peristaltic-pump, World Precision Instruments Inc., Sarasota, Florida, USA) with prewarmed $\left(37^{\circ} \mathrm{C}\right)$ oxygenated $\left(95 \% \mathrm{O}_{2} / 5 \% \mathrm{CO}_{2}\right)$ Krebs solution. Tissues were allowed to equilibrate for 90-120 minutes before the start of the experiments. Capillary glass microelectrodes (borosilicate glass capillaries, $1.0 \mathrm{~mm}$ outer diameter $\times 0.58 \mathrm{~mm}$ inner diameter; Clark Electromedical Instruments, Edenbridge, United Kingdom) were made using a microelectrode puller (model P-97, 3-mm-wide filament; Sutter Instrument Co., Novato, California, USA), were filled with $\mathrm{KCl}(3 \mathrm{mM})$, and had resistances in the range 80-120 $\mathrm{M} \Omega$. Resting membrane potentials (RMPs) of circular smooth muscle cells were recorded against a ground $\mathrm{Ag}-\mathrm{AgCl}$ electrode placed in the bath medium as described in detail in ref. 33. Membrane potentials were amplified (DUO 733 microelectrode amplifier; World Precision Instruments Inc.) and digitalized with an analogue-to-digital converter (SCB-68 interface; National Instruments Corp., Austin, Texas, USA). Permanent recordings of membrane potentials were made on a personal computer running the LabVIEW 5.0 program (National Instruments Corp.).

Statistical analysis. Results are expressed as mean \pm SEM and were compared using Student's $t$ test. $P$ values less than 0.05 were considered statistically significant.

\section{Results}

Genetic and pharmacological blockade of CB1 signaling increases severity of induced colitis. In order to study the involvement of CB1 and the endogenous cannabinoid system in colon inflammation, we first used CB1-deficient mice in the DNBS model of colitis. Intrarectal administration of $100 \mu \mathrm{l}$ of $50 \%$ ethanol did not induce detectable inflammation in $\mathrm{CB1}^{-/-}$nor in $\mathrm{CB}^{+/+}$mice, as macroscopically evaluated (data not shown). Conversely, after intrarectal administration of DNBS (5 $\mathrm{mg}$ per mouse), macroscopic evaluation of $\mathrm{CB} 1^{-/-}$colons revealed stronger inflammation as compared with $\mathrm{CB} 1^{+/+}$colons (Figure $1 \mathrm{~A}$ ). Macroscopic score in $\mathrm{CB}^{-/-}$mice was 2.2-fold higher than in $\mathrm{CB}^{+/+}$mice $\left(C B 1^{+/+}, 1.7 \pm 0.2\right.$, vs. $\mathrm{CB1} 1^{-/-}$, $3.7 \pm 0.3, P<0.05$; Figure $1 \mathrm{~A})$. MPO assay revealed that the degree of inflammation was higher in $\mathrm{CB1}^{-/-}$than in $\mathrm{CB1} 1^{+/+}$mice $\left(\mathrm{CB1}^{+/+}\right.$, $100 \% \pm 37 \%$, vs. $C B 1^{-/-}, 230 \% \pm 54 \%, P<0.05$; Figure $\left.1 B\right)$. Histological analysis confirmed these observations, showing no differ-

\section{Figure 1}

DNBS- and DSS-induced colitis is worsened in CB1 $1^{-/}$and in SR141716A-treated $(3 \mathrm{mg} / \mathrm{kg}$ ) C57BL/6N mice. (A and B) Macroscopic score of colonic inflammation $(\mathbf{A})$ and levels of MPO activity (B) in $\mathrm{CB} 1^{+/+}$and $\mathrm{CB} 1^{-/-}$littermates. (C and D) Macroscopic score of colonic inflammation (C) and levels of MPO activity (D) in vehicle- and SR141716A-treated C57BL/6N mice. Data are means \pm SEM.
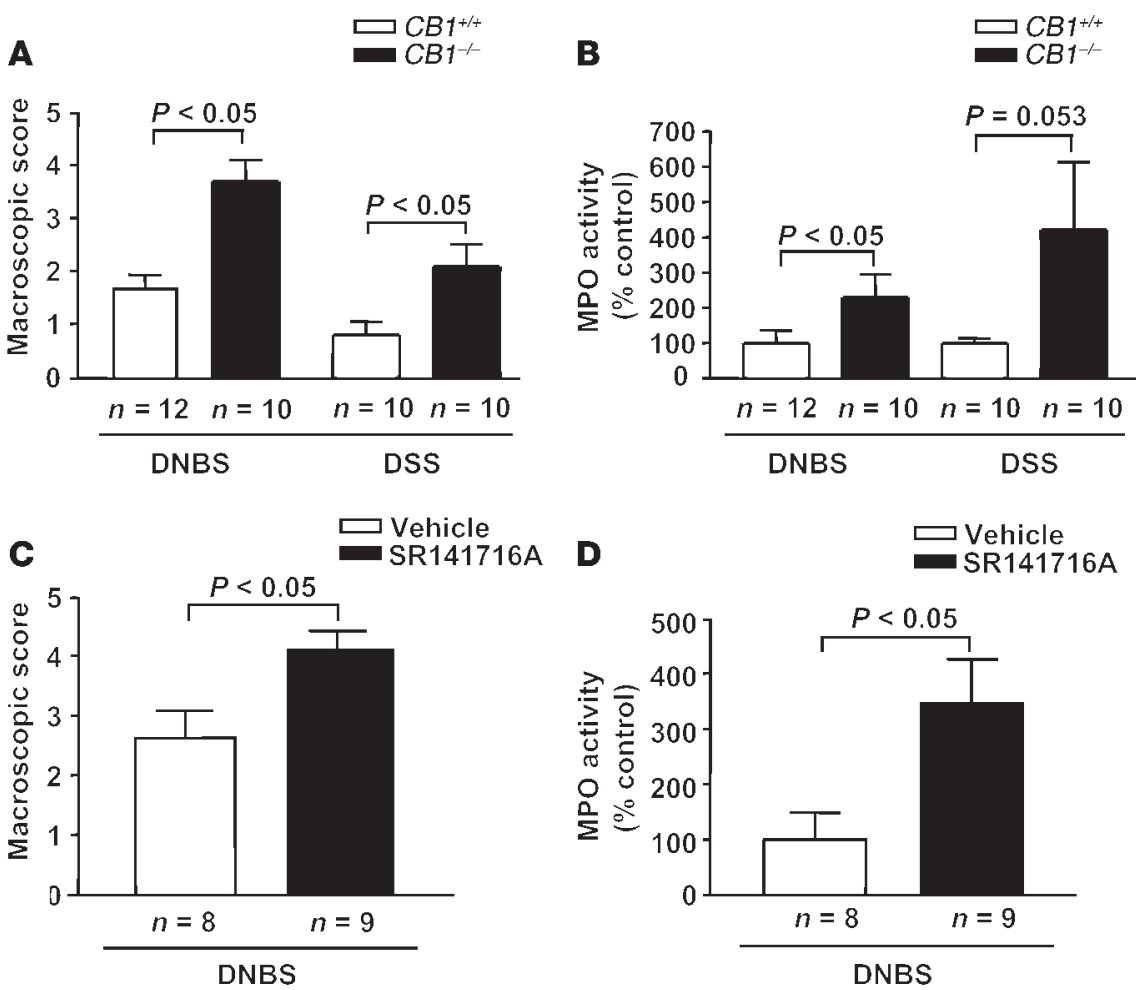


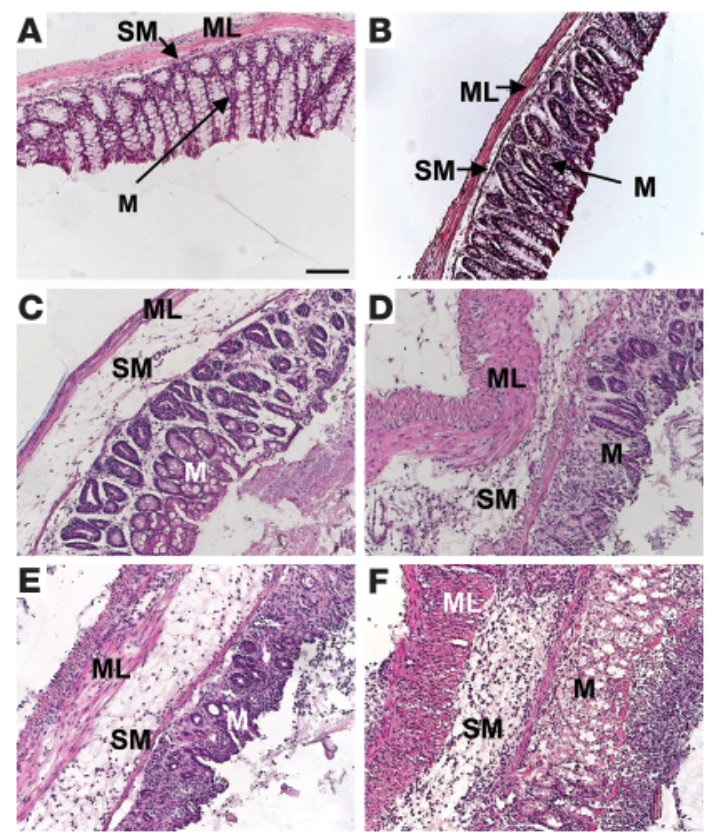

ences between genotypes in untreated colons (Figure 2, A and B) and dramatically increased inflammatory signs in DNBS-treated $\mathrm{CB1}^{-/-}$as compared with $\mathrm{CB} 1^{+/+}$colons (Figure 2 , C and D). In particular, a notable disruption of the epithelial structure with extensive hemorrhagic necrosis and infiltration of neutrophils into the mucosa was detected in $\mathrm{CB1}^{-/-}$colons, with acute inflammation extending into the submucosa and the muscle layer.

To further substantiate the general involvement of CB1 signaling in colon inflammation, we characterized the development of colitis in CB1-deficient mice subjected to oral DSS treatment ( $5 \%$ in drinking water) for 7 days. Macroscopic evaluation of $\mathrm{CB}^{-/-}$ colons revealed stronger inflammation as compared with $\mathrm{CB} 1^{+/+}$ colons (Figure 1A). Macroscopic score in $\mathrm{CB}^{-/-}$was more than twofold higher than in $\mathrm{CB1}^{+/+}$mice $\left(\mathrm{CB1}^{+/+}, 0.8 \pm 0.2\right.$, vs. $\mathrm{CB1} 1^{-/-}$, $2.1 \pm 0.4, P<0.05)$. MPO assay showed that the degree of inflammation was higher in $\mathrm{CB1}^{-/-}$than in $\mathrm{CB1}^{+/+}$mice, although the difference did not reach statistical significance $\left(C B 1^{+/+}, 100 \% \pm 14.9 \%\right.$, vs. $C B 1^{-/}, 423.5 \% \pm 189.8 \%, P=0.053$; Figure $\left.1 \mathrm{~B}\right)$.

In order to check for the acute involvement of $\mathrm{CB} 1$ in protection against inflammation, we treated wild-type $\mathrm{C} 57 \mathrm{BL} / 6 \mathrm{~N}$ mice with the specific CB1 antagonist SR141716A $(3 \mathrm{mg} / \mathrm{kg}) 30$ minutes before and 24 and 48 hours after intrarectal administration of DNBS. Treatment with SR141716A induced stronger inflammation than treatment with vehicle. This was shown both by macroscopic scoring of inflammatory signs (vehicle, $2.6 \pm 0.5$, vs. SR141716A, $4.1 \pm 0.3, P<0.05$; Figure $1 \mathrm{C}$ ) and by MPO analysis (vehicle, $100 \% \pm 48.4 \%$, vs. SR141716A, $346.6 \% \pm 79.5 \%, P<0.05$; Figure 1D). Histological analysis of inflamed colons confirmed these observations, revealing a more severe transmural colitis in SR141716A-treated specimens, with thickening of the bowel wall, inflammatory infiltrates, and stronger increase in lymphoid-follicle size, associated with adherence to surrounding tissues, as compared with vehicle-treated controls (Figure 2, E and F).

DNBS-induced colitis is reduced by administration of the potent cannabinoid agonist HU210 as well as in FAAH-deficient mice. If the endogenous cannabinoid system plays an important role in the pathophysiological protection from DNBS-induced colitis, it is conceivable that

\section{Figure 2}

Histological micrographs showing $\mathrm{H} \& \mathrm{E}$ staining from transverse sections of the colon. (A and $\mathbf{B})$ Colons from $\mathrm{CB}^{+/+}(\mathbf{A})$ and $\mathrm{CB1} 1^{-1-}(\mathbf{B})$ mice without DNBS treatment. (C and D) Colons from $C B 1^{+/+}$(C) and $C B 1^{-/-}$(D) mice 3 days after DNBS treatment. ( $E$ and $\mathbf{F}$ ) Colons from vehicle-treated $(\mathbf{E})$ and SR141716A-treated $(3 \mathrm{mg} / \mathrm{kg})(\mathbf{F})$ C57BL/6N mice 3 days after DNBS treatment. In particular, note the severe mucosal infiltration with inflammatory cells, severe submucosal edema, and vascular alterations in $\mathrm{CB}^{-1-}$ and SR141716A-treated mice. ML, muscular layer; M, mucosa; SM, submucosa. Scale bar: $100 \mu \mathrm{m}$.

stimulation of cannabinoid receptors during inflammatory processes might decrease the level of inflammation. Therefore, we treated C57BL/6N wild-type mice with the potent cannabinoid agonist HU210 $(0.05 \mathrm{mg} / \mathrm{kg}) 30$ minutes before and 24 and 48 hours after intrarectal administration of DNBS. Treatment with HU210 markedly reduced the levels of inflammation as compared with treatment with vehicle, as revealed by macroscopic scoring (vehicle, $3.7 \pm 0.5$, vs. HU210, $1.8 \pm 0.3, P<0.05$; Figure $3 \mathrm{~A}$ ) and by MPO assay (vehicle, $100 \% \pm 39 \%$, vs. HU210, $5.4 \% \pm 2.7 \%, P<0.05$; Figure $3 \mathrm{~B}$ ). Moreover, we analyzed the response to DNBS-induced inflammation in FAAH-deficient $\left(F A A H^{-/}\right)$mice, which are profoundly impaired in their ability to degrade anandamide (23). The macroscopic score in $F A A H^{-1-}$ mice was 2.0-fold lower than in $\mathrm{FAAH}^{+/+}$littermates $\left(F A A H^{+/+}, 3.8 \pm 0.8\right.$, vs. $\mathrm{FAAH}^{-/-}, 1.9 \pm 0.5, P<0.05$; Figure $3 \mathrm{C})$. MPO assay confirmed that the degree of inflammation was higher in $\mathrm{FAAH}^{+/+}$than in $\mathrm{FAAH}^{-/-}$mice $\left(\mathrm{FAAH}^{+/+}, 100 \% \pm 32 \%\right.$, vs. $F A A H^{-/-}, 22 \% \pm 16 \%, P<0.05$; Figure $\left.3 \mathrm{D}\right)$.

CB1 and Enk $m R N A$ levels are upregulated in the colon after DNBSinduced inflammation. Using ISH, the levels of CB1 transcripts were evaluated at a single-cell resolution in colons of $\mathrm{CB}^{+/+}$mice either in control conditions or 3 days after intrarectal administration of DNBS. In control colons, CB1 mRNA was predominantly expressed
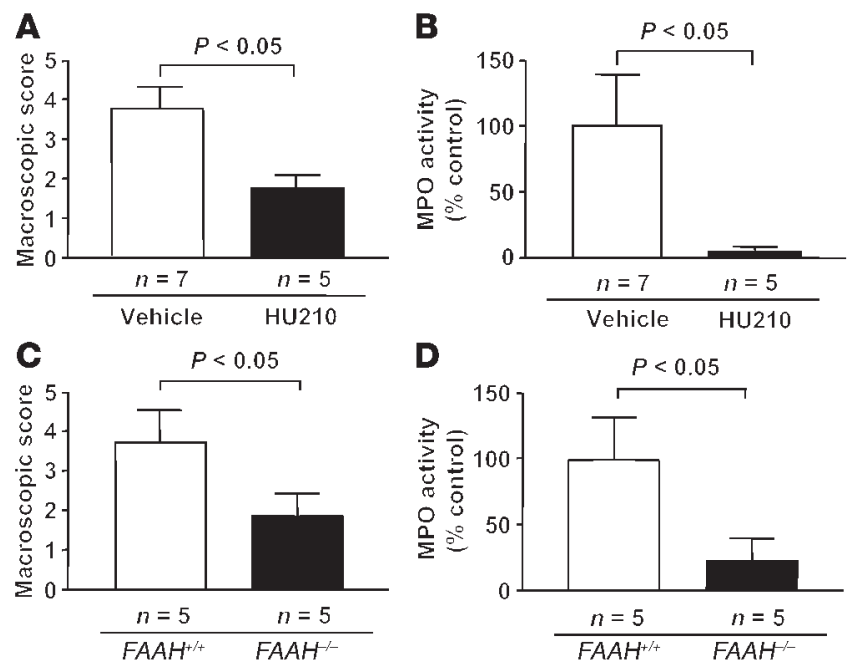

\section{Figure 3}

Pharmacological stimulation of cannabinoid receptors and genetic enhancement of endocannabinoid levels protect against DNBS-induced colitis. (A and B) Macroscopic score of colonic inflammation $(\mathbf{A})$ and levels of MPO activity (B) in vehicle-treated and HU210-treated (0.05 $\mathrm{mg} / \mathrm{kg}$ ) C57BL/6N mice. (C and D) Macroscopic score of colonic inflammation (C) and levels of MPO activity (D) in $F A A H^{+/+}$and $F A A H^{-/-}$mice. Data are means \pm SEM. 

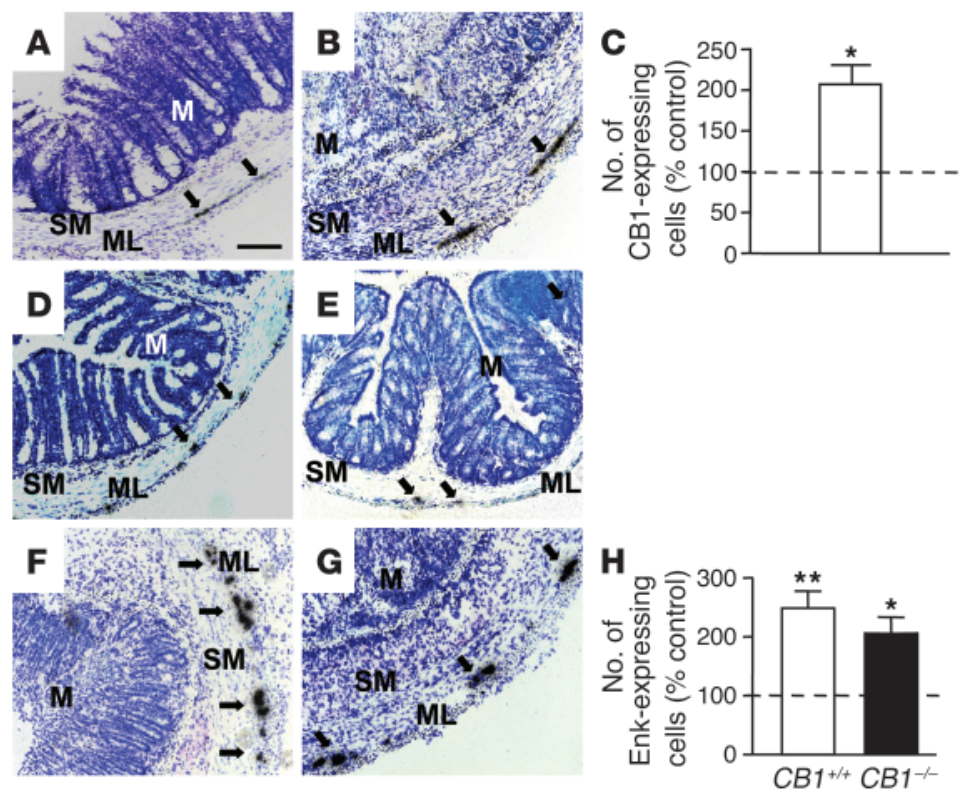

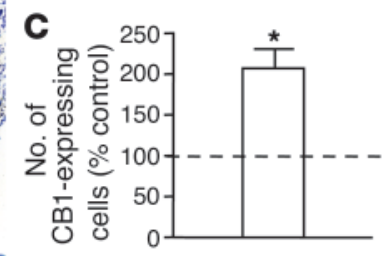

Figure 4

Relative numbers of CB1- and Enk-expressing myenteric neurons are increased 3 days after DNBS treatment, as detected by ISH. (A and B) Micrographs showing CB1 mRNA in untreated (A) and in DNBS-treated (B) $C B 1^{+/+}$mice. (C) Quantitative evaluation of $\mathrm{CB} 1$-expressing cells in the myenteric plexuses of DNBS-treated $\mathrm{CB} 1^{+/+}$mice (white bar, $n=3$ ). (D-G) Micrographs showing Enk mRNA in untreated $\mathrm{CB} 1^{+/+}(\mathrm{D})$, untreated $\mathrm{CB}^{-/-}(\mathrm{E})$, DNBS-treated $\mathrm{CB} 1^{+/+}(\mathbf{F})$, and DNBS-treated $\mathrm{CB1}^{-/-}(\mathbf{G})$ colons. $(\mathbf{H})$ Quantitative evaluation of Enk-expressing cells in the myenteric plexuses of DNBS-treated $\mathrm{CB} 1^{+/+}$ (white bar, $n=3$ ) and $C B 1^{-1-}$ (black bar, $n=3$ ) mice. Values are means \pm SEM. ${ }^{*} P<0.05,{ }^{* \star} P<0.01$ vs. respective untreated controls. Dotted lines, $100 \% . n=3$ per group. Arrows: CB1- and Enk-expressing cells. Scale bar: $100 \mu \mathrm{m}$. in neurons belonging to the myenteric plexus (Figure 4A). After DNBS-induced inflammation, an increase in the number of CB1expressing cells was observed (Figure 4B). Counting of single CB1expressing cells confirmed this observation (untreated, $100 \% \pm 17.5 \%$, vs. treated, $205.2 \% \pm 22.9 \%, P<0.05$; Figure $4 \mathrm{C}$ ).

The endogenous opioidergic system was recently shown to participate in the protection against inflammation in the TNBS model of colitis through the activation of $\mu$-opioid receptors (34). To test whether the protective functions of the endogenous cannabinoid system involve the activation of endogenous opioid signaling, we analyzed Enk mRNA-expressing neurons in untreated and DNBS-treated colons derived from both $\mathrm{CB}^{+/+}$and $\mathrm{CB1}^{-/-}$ mice. In untreated colons, the number of cells expressing Enk was not different between genotypes $\left(C B 1^{+/+}, 100 \% \pm 18.9 \%\right.$, vs. $C B 1^{-/-}$, $109.3 \% \pm 17.1 \%, P>0.05$; Figure 4, D and E). After DNBS treatment, the number of Enk-expressing cells was significantly increased in both $\mathrm{CB} 1^{+/+}$colons $(249.0 \% \pm 28.7 \%, P<0.01$ vs. untreated $\mathrm{CB1}^{+/+}$; Figure $\left.4 \mathrm{H}\right)$ and $C B 1^{-/-}$colons $(205.7 \% \pm 27.9 \%$, $P<0.05$ vs. untreated $\mathrm{CB}^{-1-} ;$ Figure $\left.4 \mathrm{H}\right)$. After DNBS treatment, the number of Enk-expressing cells was significantly increased both in $\mathrm{CB}^{+/+}$colons $(249.0 \% \pm 28.7 \%, P<0.01$ vs. untreated $\mathrm{CB} 1^{+/+}$; Figure 4, $\mathrm{F}$ and $\left.\mathrm{H}\right)$ and in $\mathrm{CB1} 1^{-/-}$colons $(205.7 \% \pm 27.9 \%$, $P<0.05$ vs. untreated $C B 1^{-/-}$; Figure $4, \mathrm{G}$ and $\mathrm{H}$ ).

Counts of myenteric neurons were carried out in parallel, on cuprolinic blue-stained sections adjacent to the ones used for ISH. Comparable numbers of neurons were shown per unit length of serosa in DNBS-treated versus untreated colons, as well as in $\mathrm{CB1}^{+/+}$ versus $C B 1^{-/-}$mice (untreated $C B 1^{+/+}, 100 \% \pm 5.1 \%$; treated $C B 1^{+/+}$, $120.7 \% \pm 11.6 \%$; untreated $C B 1^{-/-}, 97.8 \% \pm 5.7 \%$; treated $C B 1^{-/}$, $109.2 \% \pm 6.4 \% ; P>0.1$ for all comparisons); thus, no overt changes were shown in overall neuronal populations.

\section{Figure 5}

Temporal development of DNBS-induced colitis in $\mathrm{CB}^{-/-}$and $\mathrm{CB} 1^{+/+}$ mice. (A) Macroscopic score, (B) MPO activity, and (C) body-weight changes at different time points after induction of colitis. Values are means \pm SEM. ${ }^{*} P<0.05$.
Time-course analysis of DNBS-induced colitis. Three days after intrarectal administration of DNBS, inflammatory responses appear to be modulated by the endogenous cannabinoid system. This time point was chosen because maximal acute DNBS-induced inflammation has been reported in mice after 3 days (35). However, the involvement of CB1 at different stages of the inflammatory process is still an open question. Macroscopic scoring, MPO activ-

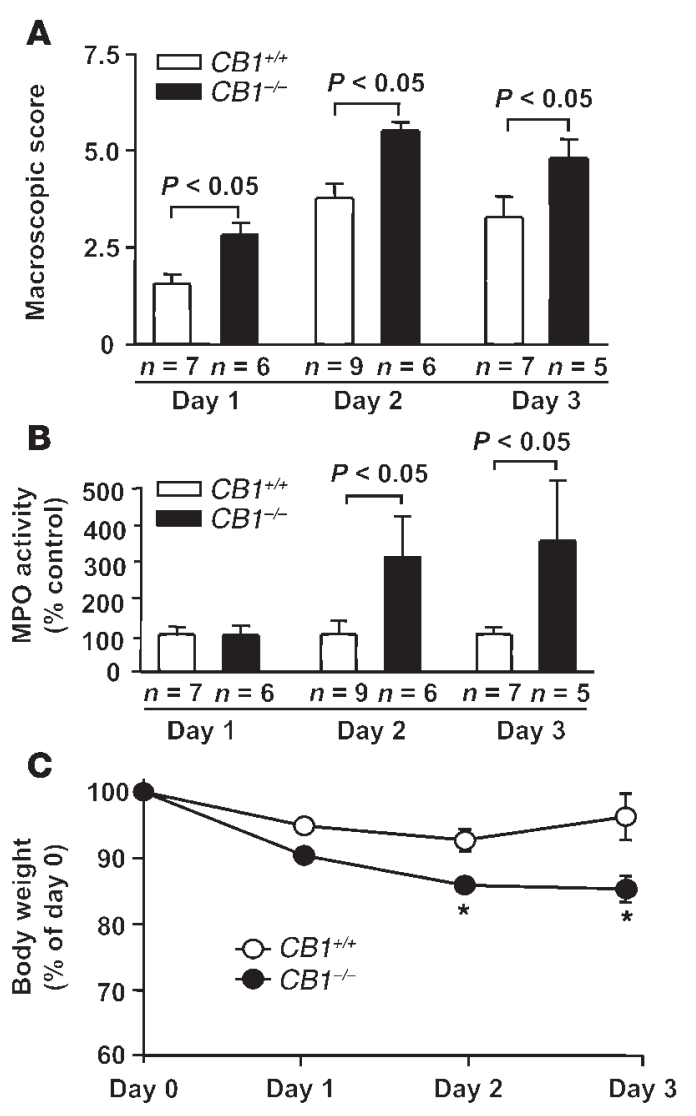




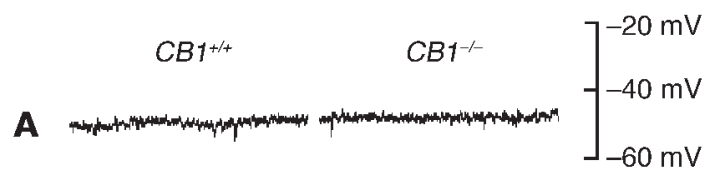

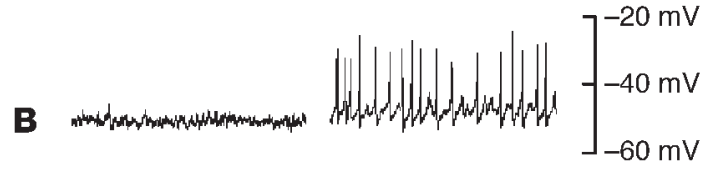

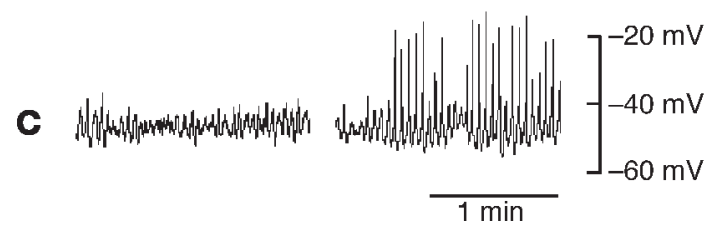

Figure 6

Intracellular recordings from circular smooth muscles in distal colon of $\mathrm{CB}^{+/+}$and $\mathrm{CB} 1^{-/-}$mice to monitor RMPs. Representative traces are shown for mice before (A), 8 hours after (B), and 24 hours after (C) induction of colitis. In $\mathbf{B}$ and $\mathbf{C}$, note the occurrence of oscillatory action potentials in $\mathrm{CB} 1^{-/}$colons.

ity, and body-weight loss were analyzed during a 3-day time course in $\mathrm{CB}^{+/+}$and $\mathrm{CB}^{-/-}$littermates (Figure 5). On day 1, macroscopic evaluation revealed a significant difference between genotypes $\left(\mathrm{CB1}^{+/+}, 1.6 \pm 0.2\right.$, vs. $\mathrm{CB1} 1^{-/}, 2.8 \pm 0.3, P<0.05$; Figure $\left.5 \mathrm{~A}\right)$, whereas no significant difference was found in colonic MPO levels (Figure 5B) and body-weight loss (Figure 5C) between genotypes. By contrast, on day 2 and day 3 , significant differences were found in the analysis of macroscopic score (day 2 : $C B 1^{+/+}, 3.7 \pm 0.3$, vs. $C B 1^{-/-}$, $5.5 \pm 0.2, P<0.05$; day $3: \mathrm{CB1}^{+/+}, 3.2 \pm 0.5$, vs. $\mathrm{CB1}^{-/-}, 4.8 \pm 0.5, P<0.05$; Figure $5 \mathrm{~A}$ ), in MPO activity (day $2: \mathrm{CB1}^{+/+}, 100 \% \pm 36 \%$, vs. $C B 1^{-/-}$, $314 \% \pm 105 \%, P<0.05$; day $3: \mathrm{CB1}^{+/+}, 100 \% \pm 20 \%$, vs. $\mathrm{CB} 1^{-/-}$, $354 \% \pm 163 \%, P<0.05$; Figure $5 \mathrm{~B}$ ), and in body-weight loss (day 2: $\mathrm{CB1}^{+/+},-7.3 \% \pm 1.6 \%$, vs. $\mathrm{CB1}^{-/-},-14.1 \% \pm 0.7 \%, P<0.05$; day $3: \mathrm{CB}^{+/+}$, $-3.8 \% \pm 3.5 \%$, vs. $C B 1^{-/},-14.7 \% \pm 2.0 \%, P<0.05$; Figure $5 C$ ). Therefore, macroscopic inflammatory signs were stronger in $\mathrm{CB}^{-/-}$ already 24 hours after the inflammatory insult, whereas the effects of the lack of CB1 on MPO levels and body-weight loss required a longer period of time to become evident. Additionally, the regaining of body weight of $\mathrm{CB1}^{+/+}$mice on day 3 was absent in $\mathrm{CB1}^{-/-}$ mice (Figure 5C), suggesting that $\mathrm{CB} 1$ might play a role in the recovery from colonic inflammation to reconstitute general health.

Electrophysiological analysis shows spontaneous oscillatory activities in $\mathrm{CB} 1^{-1-}$ mice at early stages of colonic inflammation. Circular smooth muscle cells of uninflamed $C B 1^{+/+}$mice displayed a stable RMP of $-51.6 \pm 0.9 \mathrm{mV}(n=4)$, which was not different from the RMP measured in $C B 1^{-/-}$mice $(-51.1 \pm 0.6 \mathrm{mV}, n=4, P>0.05$; Figure $6 \mathrm{~A})$. Additionally, 8 hours and 24 hours after DNBS treatment, RMP was not different between genotypes ( 8 hours: $C B 1^{+/+},-50.0 \pm 1.4$ $\mathrm{mV}$, vs. $C B 1^{-/},-51.3 \pm 0.3 \mathrm{mV}, n=4, P>0.05$; Figure $6 \mathrm{~B}$; 24 hours: $\mathrm{CB} 1^{+/+},-55.0 \pm 1.2 \mathrm{mV}$, vs. $C B 1^{-/-},-53.4 \pm 1.5 \mathrm{mV}, n=3, P>0.05$; Figure $6 \mathrm{C}$ ). In both genotypes, RMP was not changed in the presence of atropine $(1 \mu \mathrm{M})$, an inhibitor of cholinergic transmission (data not shown). After DNBS treatment, however, $\mathrm{CB}^{-/-}$mice displayed spontaneous action potentials with a frequency of $26.8 \pm 2.9 \mathrm{~min}^{-1}$ and an amplitude of $28.8 \pm 3.9 \mathrm{mV} 8$ hours after initiation of inflammation $(n=5)$, and a frequency of $40.4 \pm 1.2 \mathrm{~min}^{-1}$ and an amplitude of $29.3 \pm 2.6 \mathrm{mV} 24$ hours after initiation of inflammation $(n=5)$. These spontaneous action potentials were not observed in $\mathrm{CB}^{+/+}$mice at any time point after DNBS treatment or in untreated mice (Figure 6). The rhythmic action potentials were unchanged in the presence of atropine $(1 \mu \mathrm{M})$ (data not shown).

\section{Discussion}

Upon inflammatory insults, several different cellular pathways are activated in the intestinal tract, leading to a pathological state (36). However, simultaneous protective mechanisms are also activated, and the balance between pro- and anti-inflammatory responses determines the outcome of the pathological processes (37).

In this study, we analyzed the involvement of the endogenous cannabinoid system in the development of experimental colitis in mice, induced by intrarectal DNBS treatment and oral DSS application. Genetic ablation of CB1 receptors rendered mice more sensitive to inflammatory insults, indicating a protective role of the CB1 receptors during inflammation. This protection was mediated by an acute activation of the endogenous cannabinoid system rather than being caused by developmental defects due to the lifelong absence of CB1 receptors, since pharmacological blockade of CB1 with the specific antagonist SR141716A led to a worsening of colitis that was similar to that observed in CB1-deficient mice. The involvement of the endogenous cannabinoid system in the modulation of the acute phase of DNBS-induced colitis is further supported by the increased levels of transcripts coding for CB1 in wild-type mice after induction of inflammation. By ISH experiments, the number of CB1-expressing cells was found to be significantly increased after inflammation, without any simultaneous significant increase of the total number of neurons. Thus, it appears that neurons that express undetectable or very low levels of CB1 receptor in basal conditions, start to express this receptor to enhance endocannabinoid signaling.

The protective role of the endogenous cannabinoid system was observed 24 hours after DNBS treatment and became more evident on day 2 and day 3 . However, increased spontaneous spiking activity of smooth muscle cell membrane of DNBS-treated colons from $C B 1^{-/-}$mice was already visible 8 hours after DNBS treatment, indicating that inflammation-induced irritation of smooth muscle occurs at an earlier stage than in wild-type mice. This gives further support to the notion that the endogenous cannabinoid system is protective against inflammatory changes. These data indicate that the activation of CB1 and of the endogenous cannabinoid system is an early and important physiological step during self-protection of the colon against inflammation.

The occurrence of dysmotility in inflammatory diseases of the small or the large intestine is widely accepted. Contractility of smooth muscle to cholinergic or tachykinergic stimuli is increased in the early stages and decreased in the later stages of inflammation $(38,39)$, and contractility following electrical neuronal stimulation in the inflamed gut is increased (40). The electrophysiological changes in the distal colon, as used in this study, show increased smooth muscular excitability, leading to the occurrence of spontaneous spiking activity. This kind of irritation was recently described for guinea pig distal colonic neurons, leading to the suggestion that dysmotility in inflamed colon is due to a disruption of the afferent limb of the intrinsic motor reflexes (41). In these changes, the release of tachykinins from capsaicin-sensitive neurons might play a major role (42), whereas cholinergic mechanisms seem not to be involved. These observations are in good agreement with our results, suggesting a cholinergic-independent mechanism, since the spiking activi- 
ty was not changed after atropine application. Consistent with this hypothesis, CB1 receptors, identified by immunohistochemistry on substance P-containing neurons (43), have been shown to be involved in the noncholinergic control of intestinal motility (44).

In the small intestine, an involvement of CB1 receptors in the control of intestinal motility during croton oil-induced inflammation was recently evidenced. Izzo et al. showed that pharmacological administration of cannabinoids is able to delay gastrointestinal transit in croton oil-treated mice (45). Increased levels of CB1 receptor expression in inflamed jejuna may contribute to this protective effect (45). However, this work was not able to reveal a physiological protective action of the endogenous cannabinoid system against enteritis, since administration of the CB1 antagonist SR141716A alone failed to specifically worsen inflammation-induced gut hypermotility. By applying genetic and pharmacological approaches, our present investigation extended the observations by Izzo et al. (45) to the large intestine and, using morphological criteria, MPO measurements, and electrophysiological recordings, included the determination of inflammatory responses in the absence of a functional endogenous cannabinoid system. Most importantly, we were able to clearly show a physiological protective role of the endogenous cannabinoid system against intestinal inflammation.

A protective role against colon inflammation was recently shown for the endogenous opioidergic system (34), and a crosstalk between endogenous cannabinoid and opioid systems has been proposed (46). We found that DNBS treatment increased the levels of mRNA encoding the endogenous opioid Enk in the colon. This increase was present in DNBS-treated colons of both genotypes, indicating that $\mathrm{CB} 1$ receptors are not necessary to induce the increase in Enk mRNA levels during inflammatory processes. However, these results do not exclude a possible cross-talk between the two protective endogenous systems, and further investigations are needed to clarify this issue.

FAAH is the major enzyme involved in the degradation of several bioactive fatty amides, in particular of anandamide (47), and its genetic deletion in mice leads to strongly decreased ability to degrade this endocannabinoid and to an increase of anandamide levels in several tissues (23). FAAH-deficient mice showed significant protection against DNBS treatment. Moreover, pharmacological stimulation of cannabinoid receptors with the potent agonist HU210 also induced a reduction of experimental colitis. Anandamide is believed to act not only through CB1 receptors, but also through other targets, including the peripheral cannabinoid receptor CB2 and the vanilloid receptor TRPV1 (48). On the other hand, HU210 is also able to stimulate CB2 (13). Therefore, it cannot be excluded that decreased inflammation in $\mathrm{FAAH}^{-/-}$mice and the anti-inflammatory actions of HU210 are due to the activation of other targets than CB1 receptors. However, our data from $\mathrm{CB1}^{-/-}$and SR141716A-treated mice clearly point to a central role of $\mathrm{CB} 1$ in the physiological control of colonic inflammation. A recent investigation showed that cholera toxin-induced accumulation of intestinal fluid in mice is modulated by activation of the endogenous cannabinoid system acting through CB1, but not through TRPV1 nor CB2, receptors (49). Moreover, CB1 receptors were also shown to modulate gastrointestinal motility during croton oil-induced inflammation in mice (45). However, conclusive results regarding the involvement of TRPV1 in protective signaling cascades after DNBS treatment should be possible using TRPV1-deficient mice.

The ability of cannabinoid receptor agonists to suppress peritoneal inflammation and to inhibit inflammation-induced gastrointestinal hypermotility when administered intracerebroventricularly has recently been shown $(45,50)$, indicating that cannabinoids may also act in the CNS to exert their anti-inflammatory activities. As we used systemic treatments and mutant mice bearing gene deletions in all cells of the body, we cannot exclude a central component of the antiinflammatory effects of the endogenous cannabinoid system during DNBS-induced colitis. However, the early alterations in electrophysiological properties of inflamed $\mathrm{CB1}^{-/}$colons and the increased levels of CB1 mRNA in myenteric plexuses of DNBS-treated colons seem to point to an important, if not predominant, function of the endogenous cannabinoid system at peripheral sites. Use of central administration of drugs or, conversely, of cannabinoid agonists and antagonists unable to cross the blood-brain barrier, or the generation of conditional CB1 mutant mice with tissue-specific deletion of the gene, will help to clarify this important issue.

In conclusion, this study shows that the endogenous cannabinoid system is physiologically involved in the protection against excessive inflammation in the colon, both by dampening smooth muscular irritation caused by inflammation and by controlling cellular pathways leading to inflammatory responses. These results strongly suggest that modulation of the physiological activity of the endogenous cannabinoid system during colonic inflammation might be a promising therapeutic tool for the treatment of several diseases characterized by inflammation of the gastrointestinal tract.

\section{Acknowledgments}

We thank A.A. Izzo, C. Brancia, E. Sanna, D. Cota, and U. Pagotto for discussions and suggestions, and A. Daschner and B. Wölfel for their excellent technical assistance, mouse breeding, and genotyping. This work was supported by grants from the Deutsche Forschungsgemeinschaft (LU755/1-3) and the Vigoni program (2002; DAAD-CRUI), and by a scholarship from the Hertie Foundation (to B. Lutz).

Received for publication July 11, 2003, and accepted in revised form February 3, 2004.

Address correspondence to: Beat Lutz, Max Planck Institute of Psychiatry, Kraepelinstrasse 2-10, 80804 Munich, Germany. Phone: 49-89-30-622-640; Fax: 49-89-30-622-610; E-mail: lutz@mpipsykl.mpg.de.

Federico Massa and Giovanni Marsicano contributed equally to this work.

\footnotetext{
1. Drosmann, D.A., Corazzieri, E., Talley, N.J., Thompsom, W.G., and Whitehead, W.E. 2000. Rome II. The functional gastrointestinal disorders. Diagnosis, pathophysiology and treatment: a multinational consensus. 2nd edition. Degnon Associates. McLean, Virginia, USA. 370 pp.

2. Mayer, E.A., and Collins, S.M. 2002. Evolving pathophysiologic models of functional gastrointestinal disorders. Gastroenterology. 122:2032-2048.

3. Barbara, G., De Giorgio, R., Stanghellini, V., Cremon, C., and Corinaldesi, R. 2002. A role for inflammation in irritable bowel syndrome? Gut. 51:41-44.

4. Selve, N. 1992. Chronic intrajejunal TNBS application in TNBS-sensitized rats: a new model of chronic inflammatory bowel diseases. Agents Actions. Spec No:C15-C17.

5. Sartor, R.B. 1991. Animal models of intestinal
}

inflammation. Relevance to inflammatory bowel disease. In Inflammatory bowel disease. R.P. MacDermott and W.F. Stenson, editors. Elsevier Science. New York, New York, USA. 337-353.

6. Zurier, R.B. 2003. Prospects for cannabinoids as anti-inflammatory agents. J. Cell. Biochem. 88:462-466.

7. Richardson, J.D., Kilo, S., and Hargreaves, K.M. 1998. Cannabinoids reduce hyperalgesia and 
inflammation via interaction with peripheral CB1 receptors. Pain. 75:111-119.

8. Di Carlo, G., and Izzo, A.A. 2003. Cannabinoids for gastrointestinal diseases: potential therapeutic applications. Expert Opin. Investig. Drugs. 12:39-49.

9. Abel, E.L. 1980. Marijuana: the first twelve thousand years. Plenum Press. New York, New York, USA. 289 pp.

10. Grispoon, L., and Bakalar, J.B. 1997. Marijuana: the forbidden medicine. Yale University Press. New Haven, Connecticut, USA. 184 pp.

11. Lutz, B. 2002. Molecular biology of cannabinoid receptors. Prostaglandins Leukot. Essent. Fatty Acids. 66:123-142.

12. Piomelli, D. 2003. The molecular logic of endocannabinoid signalling. Nat. Rev. Neurosci. 4:873-884.

13. Howlett, A.C., et al. 2002. International Union of Pharmacology. XXVII. Classification of cannabinoid receptors. Pharmacol. Rev. 54:161-202.

14. Cravatt, B.F., and Lichtman, A.H. 2002. The enzymatic inactivation of the fatty acid amide class of signaling lipids. Chem. Phys. Lipids. 121:135-148.

15. Storr, M., et al. 2003. Cannabinoid receptor type 1 modulates excitatory and inhibitory neurotransmission in mouse colon. Am. J. Physiol. Gastrointest. Liver Physiol. 286:G110-G117.

16. Kulkarni-Narla, A., and Brown, D.R. 2000. Localization of CB1 cannabinoid receptor immunoreactivity in the porcine enteric nervous system. Cell Tissue Res. 302:73-80.

17. Coutts, A.A., Irving, A.J., Mackie, K., Pertwee, R.G., and Anavi-Goffer, S. 2002. Localisation of cannabinoid $\mathrm{CB}_{1}$ receptor immunoreactivity in the guinea pig and rat myenteric plexus. J. Comp. Neurol. 448:410-422.

18. Pinto, L., et al. 2002. Endocannabinoids as physiological regulators of colonic propulsion in mice. Gastroenterology. 123:227-234.

19. Jaggar, S.I., Sellaturay, S., and Rice, A.S. 1998. The endogenous cannabinoid anandamide, but not the CB2 ligand palmitoylethanolamide, prevents the viscero-visceral hyper-reflexia associated with inflammation of the rat urinary bladder. Neurosci. Lett. 253:123-126.

20. Pertwee, R.G. 2001. Cannabinoids and the gastrointestinal tract. Gut. 48:859-867.

21. Izzo, A.A., Mascolo, N., and Capasso, F. 2001. The gastrointestinal pharmacology of cannabinoids. Curr. Opin. Pharmacol. 1:597-603.

22. Marsicano, G., et al. 2002. The endogenous cannabinoid system controls extinction of aversive memories. Nature. 418:530-534.

23. Cravatt, B.F., et al. 2001. Supersensitivity to anandamide and enhanced endogenous cannabinoid signaling in mice lacking fatty acid amide hydrolase. Proc. Natl. Acad. Sci. U. S. A. 98:9371-9376.

24. Qiu, B.S., Vallance, B.A., Blennerhassett, P.A., and Collins, S.M. 1999. The role of CD4+ lymphocytes in the susceptibility of mice to stress-induced reactivation of experimental colitis. Nat. Med. 5:1178-1182.

25. Wallace, J.L., Le, T., Carter, L., Appleyard, C.B., and Beck, P.L. 1995. Hapten-induced chronic colitis in the rat: alternatives to trinitrobenzene sulfonic acid. J. Pharmacol. Toxicol. Methods. 33:237-239.

26. Bylund-Fellenius, A.C., Landström, E., Axelsson, L.G., and Midtvedt, T. 1994. Experimental colitis induced by dextran sulphate in normal and germfree mice. Microb. Ecol. Health Dis. 7:207-215.

27. Morris, G.P., et al. 1989. Hapten-induced model of chronic inflammation and ulceration in the rat colon. Gastroenterology. 96:795-803.

28. Krawisz, J.E., Sharon, P., and Stenson, W.F. 1984. Quantitative assay for acute intestinal inflammation based on myeloperoxidase activity. Assessment of inflammation in rat and hamster models. Gastroenterology. 87:1344-1350.

29. Bradley, P.P., Christensen, R.D., and Rothstein, G. 1982. Cellular and extracellular myeloperoxidase in pyogenic inflammation. Blood. 60:618-622.

30. Marsicano, G., and Lutz, B. 1999. Expression of the cannabinoid receptor $\mathrm{CB} 1$ in distinct neuronal subpopulations in the adult mouse forebrain. Eur. J. Neurosci. 11:4213-4225.

31. Hermann, H., Marsicano, G., and Lutz, B. 2002. Coexpression of the cannabinoid receptor type 1 with dopamine and serotonin receptors in distinct neuronal subpopulations of the adult mouse forebrain. Neuroscience. 109:451-460.

32. Karaosmanoglu, T., Aygun, B., Wade, P.R., and Gershon, M.D. 1996. Regional differences in the number of neurons in the myenteric plexus of the guinea pig small intestine and colon: an evaluation of markers used to count neurons. Anat. Rec. 244:470-480

33. Sibaev, A., Franck, H., Vanderwinden, J.M., Allescher, H.D., and Storr, M. 2003. Structural differences in the enteric neural network in murine colon: impact on electrophysiology. Am. J. Physiol. Gastrointest. Liver Physiol. 285:G1325-G1334.

34. Philippe, D., et al. 2003. Anti-inflammatory properties of the $\mu$ opioid receptor support its use in the treatment of colon inflammation. J. Clin. Invest. 111:1329-1338. doi:10.1172/JCI200316750.

35. Keates, A.C., et al. 2000. Interleukin 16 is up-regulated in Crohn's disease and participates in TNBS colitis in mice. Gastroenterology. 119:972-982.

36. Wood, J.D., Alpers, D.H., and Andrews, P.L. 1999.
Fundamentals of neurogastroenterology. Gut. 45:6-16.

37. Holzer, P. 2001. Gastrointestinal afferents as targets of novel drugs for the treatment of functional bowel disorders and visceral pain. Eur. J. Pharmacol. 429:177-193.

38. Myers, B.S., et al. 1997. Acute experimental colitis decreases colonic circular smooth muscle contractility in rats. Am. J. Physiol. 273:928-936.

39. Hosseini, J.M., et al. 1999. Progressive alterations in circular smooth muscle contractility in TNBSinduced colitis in rats. Neurogastroenterol. Motil. 11:347-356.

40. De Man, J.G., et al. 2001. Disturbance of the prejunctional modulation of cholinergic neurotransmission during chronic granulomatous inflammation of the mouse ileum. Br. J. Pharmacol. 133:695-707.

41. Linden, D.R., Sharkey, K.A., and Mawe, G.M. 2003. Enhanced excitability of myenteric $\mathrm{AH}$ neurones in the inflamed guinea-pig distal colon. J. Physiol. 547:589-601.

42. Holzer, P., and Holzer-Petsche, U. 1997. Tachykinins in the gut. II. Roles in neural excitation, secretion and inflammation. Pharmacol. Ther. 73:219-263.

43. Mascolo, N., et al. 2002. The endocannabinoid system and the molecular basis of paralytic ileus in mice. FASEB J. 16:1973-1975.

44. Izzo, A.A., Mascolo, N., Borrelli, F., and Capasso, F. 1998. Excitatory transmission to the circular muscle of the guinea-pig ileum: evidence for the involvement of cannabinoid CB1 receptors. Br. J. Pharmacol. 124:1363-1368.

45. Izzo, A.A., et al. 2001. Cannabinoid CB1-receptor mediated regulation of gastrointestinal motility in mice in a model of intestinal inflammation. $\mathrm{Br}$. J. Pharmacol. 134:563-570.

46. Manzanares, J., et al. 1999. Pharmacological and biochemical interactions between opioids and cannabinoids. Trends Pharmacol. Sci. 20:287-294.

47. Cravatt, B.F., et al. 1996. Molecular characterization of an enzyme that degrades neuromodulatory fattyacid amides. Nature. 384:83-87.

48. Di Marzo, V., De Petrocellis, L., Fezza, F., Ligresti, A., and Bisogno, T. 2002. Anandamide receptors. Prostaglandins Leukot. Essent. Fatty Acids. 66:377-391.

49. Izzo, A.A., et al. 2003. An endogenous cannabinoid tone attenuates colera toxin-induced fluid accumulation in mice. Gastroenterology. 125:765-774.

50. Smith, S.R., Denhardt, G., and Terminelli, C. 2001. The anti-inflammatory activities of cannabinoid receptor ligands in mouse peritonitis models. Eur. J. Pharmacol. 432:107-119. 